\title{
Operation Risk Structural Analysis and Evaluation System Construction for Multistation Integration Project
}

\author{
Weiwei Cui and Pingkuo Liu \\ College of Economics and Management, Shanghai University of Electric Power, Shanghai 200090, China \\ Correspondence should be addressed to Pingkuo Liu; pingoforever@sina.com
}

Received 11 December 2021; Revised 19 January 2022; Accepted 31 January 2022; Published 27 February 2022

Academic Editor: Qiuye Sun

Copyright (C) 2022 Weiwei Cui and Pingkuo Liu. This is an open access article distributed under the Creative Commons Attribution License, which permits unrestricted use, distribution, and reproduction in any medium, provided the original work is properly cited.

\begin{abstract}
Digitalization in the power grid sector will become a strong support in the future for the upgrading of the power industry. And, multistation integration has become a leading project in the process. However, there are some hidden risks to its security with the boom of new technologies. Risk analysis and evolution of the multistation integration have an important role in safe operation. This paper analyzes the relationship among risk factors by using both the structural equation modeling (SEM) and the chi-squared automatic interaction detector (CHAID) approach, which is more objective than subjective judgment. The result shows the following: (1) The operational risks come from 10 risk-derived sources which therefore can be qualitatively divided into 2 risk categories with 11 risk indicators. (2) Concerning the structural analysis, the main risk source of multistation integration comes from endogenous risks. (3) In terms of procedural analysis, cultural risk, information risk, and accidental risk are the most critical external risks, while performance risk and location risk are the most critical internal ones. The results of models provide a reference for engineering management in digitalization in the power grid sector.
\end{abstract}

\section{Introduction}

The power grid sector as a network hub has always been playing a prominent role in connecting the power supply-side and the power demand-side. It will promote the in-depth development of the energy and technological revolution [1]. It is showing that the value of a single substation cannot meet the resource needs of users any longer [2]. In this context, it is very important to the energy industry for multistation integration which realizes the optimal allocation of resources and improves the economic and social benefits.

The multistation integration makes full use of modern information technology to realize the interconnection of everything in the power system and greatly improve the ability of automatic data collection and flexible application $[3,4]$. However, it has a huge impact on the security of traditional single-station operations with the introduction of new technologies, for example, cloud computing, SDN, NFV, and 5G. As a result, there are many hidden dangers in its safe operation, such as traditional risks and new risks [5].
It is crucial to carry out the research on the risk evaluation of the multistation integrated operation. It can be ensured the safe, efficient, and reliable operation of the multistation integration by determining the importance of various risk indicators in different business scenarios. And it also can clarify the focus of decision-making on risk aversion through analysis by risk sources and risk indicators for the multistation integrated operation [6]. This will be a vital foundation for the economic operation and value maximization of the multistation integration.

The contributions of this paper are summarized as follows:

(1) The multistation integration project is currently in its infancy. The research on its operation risks is lacking. Therefore, this paper proposes and establishes a safety index system regarding the operational risks of the multistation integration.

(2) In the research of the multistation integrated risk system, the objective data are limited. Therefore, this 
paper builds two risk evaluation models based on the subjective data obtained from the questionnaires.

(3) With objectives of operating stability and maximizing benefits, the results of risk evaluation are presented to determine the importance of risk factors. And then, the basis of the risk aversion strategy is determined.

The rest of this study is organized as follows: Section 2 reviews the existing research on multistation integration, operation risk, chi-squared automatic interaction detection, and data mining. Section 3 proposes the conceptual models of the structural equation model and the chi-squared automatic interaction detection. Based on the subjective data collected from the questionnaire survey, Section 4 conducts the analysis and research of the data. In Section 5, the conclusions and the policy recommendations are presented.

\section{Literature Review}

The construction of multistation integration (MSI) is a gradually increasing tendency for integrated energy. The form of MSI is integration stations of power system, which is based on resources integration and facilities sharing [7]. It promotes the construction of shared enterprises based on existing substation resources by integrating the construction of data center stations, electric vehicle charging and swapping station, photovoltaic (PV) power station, etc. It has significant advantages in making full use of the remaining resources of substations, the exporting new forms of public services, and the cultivating new business growth points, etc. [8]. MIS realizes the integrated development of requirements by multiple types based on substation resources. On the one hand, it promotes the organic integration of energy flow, business flow, and data flow by integrating various energy, service, and customer resources. It can also achieve interconnection, equal sharing, the balance of supply and demand, and the optimization of energy information interaction [9]. And then, the goal of optimizing both the grid operation and the business capability can be achieved. On the other hand, it optimizes energy allocation to improve the comprehensive service levels. Eventually, it built both a development platform promoting new businesses, new formats, and new models and a shared platform including the physical, digital, and industrial forms [3]. The construction and operation of MIS can maximize resource utilization by integrating the existing substations, the resources of communication, power, and so on [10]. It also can realize the integration of energy flow, business flow, data flow, and capital flow. As stated before, it can be seen that MIS is more advantageous in contrast with the single-station operation. Therefore, integrated energy service in the form of MIS has become the new focus of both the current national energy strategy and the development of energy enterprises [11]. Owing to the complexity of the multistation integration system and the interaction of various uncertainties, it is difficult to maintain its normal operation. The multistation integration system has increased in potential operational risks with the rapid development of complexity and intelligence $[12,13]$. The prerequisite is ensuring its safe and stable operation for the advantages and maximizing benefits of MIS. So, the safety research reflecting the fluctuation of risks is essential to avoid major accidents during the operation phase [14]. Minimizing risks with the limited control cost is the primary purpose of the multistation integrated risk evaluation $[15,16]$. Before conducting risk management, it is necessary to clarify risk-derived sources and risk indicators to make preparations for the quantitative evaluation [17]. In previous studies on operation risks for the multistation integration project, there still exist some drawbacks. The existing risk management system usually adopts control partially, lags in risk evaluation, and lacks systematic structural analysis and comprehensive risk evaluation system [18]. This paper is dedicated to analyzing possible sources of risks in the multistation integrated operations, defining risk indicators, and conducting the structural and procedural analysis on the defined risk indicators.

The physical form of MIS presents both the process of technological collaboration and the function extension of "substation $\longrightarrow$ energy station $\longrightarrow$ multiservice station" [19]. The multistation integration project scientifically integrates advantageous resources. The project forms a platform with new infrastructure facilities. This platform with multibusiness and multidomain characteristics can realize the logical integration, the structural integration, the complementary advantages, and the data interconnection. It is a frontier field and an important link to realize the power grid digitalization and the high-quality development.

Since the multistation integration project presents the characteristics of "multiregion, multilevel, multilink", all parts of its operation link are interdependent [20]. The risk evolution analysis is based on the research of risk impacts that come from different levels and dimensions. And then, decision makers can decide the order of risk indicators based on the needs of stakeholders and the characteristics of the multistation integrated operation [21, 22]. In addition, they consider each risk level by level to clarify the focus of decision-making. This paper intends to use the structural equation modeling (SEM) and the data mining (DM) method to analyze both the structure and the procedure evolution analysis.

Structural equation model (SEM), a second generation of multivariate analysis, provides a new perspective on the overall research methodology [23] and has been widely used in social sciences [24]. SEM encompasses a set of multivariate statistical techniques, including factor analysis, regression, path analysis, and simultaneous equation modeling. SEM has several advantages for risk analysis. First, it can display driver analysis in the multilevel manner. SEM can divide the risks into multiple layers according to different attributes. Second, SEM can analyze the attributes that cannot be directly measured, such as the information risk and the cultural risk. In this way, the scope of data analysis can be enlarged. Third, SEM analysis can quantify the causal relationship between various attribute risks, so that they can be compared at the same level [25]. Due to the above advantages, SEM is highly suitable for analyzing the structural relationship of various risk indicators on the same dimension. 
The relationship between risk variables is developed based on the prediction test and the subjective data, and a graphical conceptual model is constructed in accordance with this relationship. Then, the conceptual model is converted to a mathematical model through SEM. The mathematical model is calibrated based on either experimental or observational data. Poor model fitting can suggest both the revision of the conceptual model and the respecification of the mathematical model. When the model fitting is satisfactory, the final SEM model is constructed.

Data mining techniques can yield the benefits of automation on existing software platforms and can be implemented on new systems as existing platforms are upgraded and new products developed [26]. When data mining tools are implemented on high-performance parallel processing systems, they can analyze massive databases in minutes. The most commonly used techniques in data mining are artificial neural networks, decision trees, genetic algorithms, nearest neighbor methods, and rule induction. Data mining techniques are usually solved by methods such as statistics, distances, decision trees, or neural networks. When the problem analyzed in this paper has many risk categories and complicated risk profiles, the decision trees algorithm is very beneficial, which analyzes easily and expresses the results intuitively. Decision trees are tree-shaped structures that represent sets of decisions. The decision tree algorithm can generate rules for the classification of a data set. Specific decision tree methods include classification and regression trees (CART) and chi-squared automatic interaction detection (CHAID) $[27,28]$. These methods provide a set of rules that can be applied to a new (unclassified) data set to predict which records will have a given outcome. CHAID modeling is an exploratory data analysis method used to study the relationships between a dependent measure and a large series of possible predictor variables that may interact. The dependent measure may be a qualitative (nominal or ordinal) indicator or a quantitative one. For qualitative variables, a series of chi-squared analyses are conducted between the dependent and the predictor variables. For quantitative variables, analysis of variance methods is used where intervals (splits) are determined optimally for the independent variables so as to maximize the ability to explain a dependent measure in terms of variance components $[29,30]$. By means of chi-squared metrics, CHAID is able to separately segment the groups classified in terms of the level of relations. Therefore, the leaves of the tree do have not binary branches but as many branches as the number of different variables in the data [31]. Accordingly, it was deemed convenient to use the CHAID algorithm method to analyze the procedure relationship of risk indicators on different dimensions in the study.

The advantages of both the SEM and the CHAID approach can make full use to complete operation risk evaluation system construction for multistation integration projects $[32,33]$. Through a large number of the subjective data from the multistation integration project, the inner characteristic and distribution rule of the risk evaluation system could be found in the statistical analysis aspect. Then, according to these statistical properties, different types of risk profiles are able to manage and control in an unambiguous way. The results of models provide a reference for engineering management in digitalization in the power grid sector.

\section{Methodology}

3.1. Risk Index System. In this article, the economic value adds (EVA) are treated as a signal for multistation integrated operation risk evaluation to establish a risk index system. Then, the risk identification is decomposed by using the value driver tree (VDT). VDT can be used as a general framework to illustrate the causal relationship between operating leverage and value evaluation indicators. On the one hand, VDT is used to decompose top performance to the level of operating leverage. On the other hand, risk identification is used to adjust the cost of capital and the risk-adjusted performance indicator (RAPM). Risk factors are therefore included in performance indicators. After the decomposition of the above-mentioned VDT, 9 main risk sources can be obtained. The analysis result is shown in Figure 1.

The standards of risk identification are determined according to the operation conditions and indicators of MIS. And qualitative analysis is carried out based on the experts' opinions from the multistation operation, power market, and 5G. Subsequently, risk indicators are qualitatively divided into 11 indicators [34,35], as shown in Table 1 .

\subsection{Evolution Analysis}

\subsubsection{Conceptual Model of SEM.}

(1) Construction of the Model. The measurement and the structural model in SEM are generally represented by a linear equation system. The matrix equations of those two submodels and their representative meanings are as follows:

$$
\mathrm{SEM}-\left[\begin{array}{l}
\text { the measurement model }-\left[\begin{array}{l}
Y=\Lambda_{Y} \eta+\varepsilon \\
X=\Lambda_{X} \xi+\delta
\end{array}\right. \\
\text { the structural model } \eta=\Gamma \xi+B \eta+\zeta .
\end{array}\right.
$$

(2) Confirmatory Factor Analysis (CFA) and Exploratory Factor Analysis (EFA). The basic principle is the determination of common factors to reduce dimensionality in factor analysis. Factor analysis includes two forms: confirmatory factor analysis (CFA) and exploratory factor analysis (EFA). Those two subanalyses cannot be completely separated. The steps are as follows:

Observed variables are identified and collected The covariance matrix (or Bravais-Pearson similarity coefficient matrix) is obtained

The covariance matrix (significance level, inverse covariance matrix, Bartlett ball test, inverse image covariance matrix, KMO measure) is verified The extraction factor method (the principal component analysis method and the principal factor analysis method) is selected 


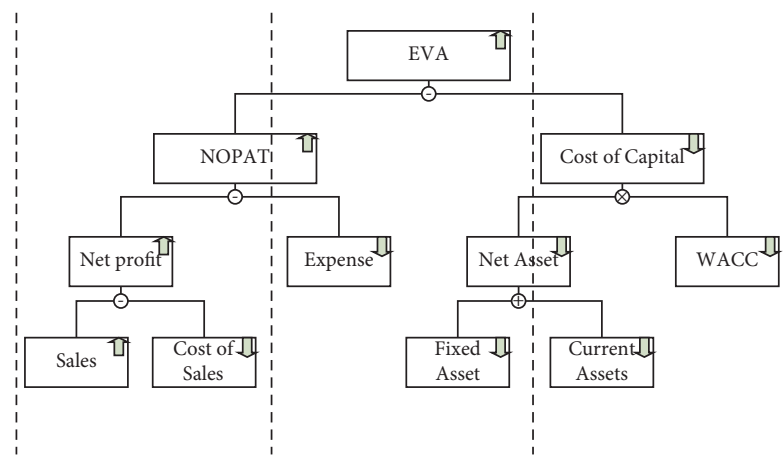

(a)

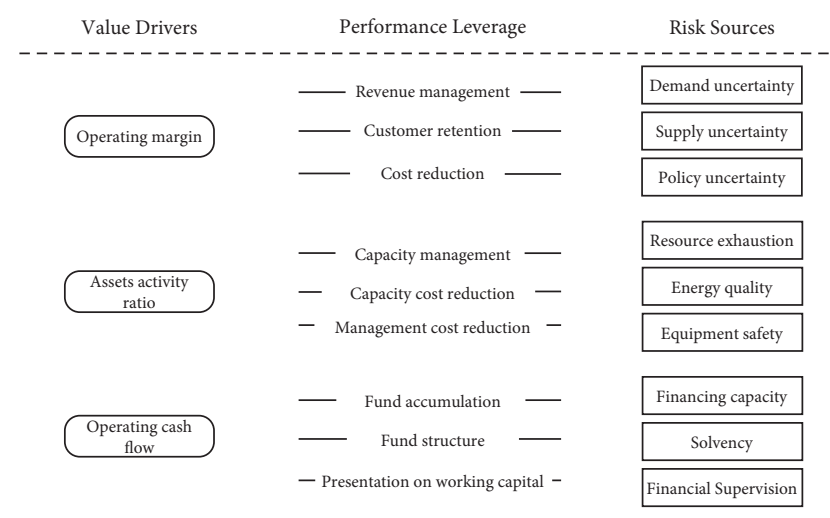

(b)

FIGURE 1: Operational performance early warning signals and risk drivers: (a) the value driver tree VDT; (b) analysis of operational risk sources.

TABLE 1: Multisituation integrated operation risk influence factor index system.

\begin{tabular}{lcc}
\hline Indicator label & Indicators & Indicator interpretation \\
\hline R1 & Information risk & Information asymmetry and serious information pollution \\
R2 & Technical risk & Technical completion rate \\
R3 & Location risk & Station selection limitation \\
R4 & Performance risk & Project schedule deviation \\
R5 & Financial risk & Project profit margin and tax rate \\
R6 & Cultural risk & Project integration progress \\
R7 & Cyclical risk & Mismatch between investment and income \\
R8 & Institutional risk & Industry development environment \\
R9 & Demand risk & Market demand indicator \\
R10 & Policy risk & Project subsidy \\
R11 & Accident risk & Unexpected disaster caused by force majeure \\
\hline
\end{tabular}

Factors and factor loads are discovered The number of extraction factors (using Kaiser's criterion and Scree test as the criteria for the number of extraction factors) is determined Extracted factors are explained

(3) Model Establishment.

Variables are set based on assumptions and verify the measurement relationship

Variable labels and the influence relations are set The path diagram is outputted

(4) Model Evaluation. In the process of evaluating the model, SEM generally uses the index of a coincidence to judge its fit degree. The index of coincidence mainly includes the chi-squared goodness-of-fit test, relative noncentrality indices (RNI), root-mean-square error of approximation (RMSEA), parsimony indices (PI), and Akaike information criterion (AIC) [36].

(5) Model Adjustment. When the coincidence index indicates that the model does not fit the data well, the model needs to be revised. The basis for the revision is as follows:

The residual analysis result is outputted by LISREL The index is revised The nest model is compared
3.2.2. Conceptual Model of CHAID. The general steps of CHAID mainly include both the preprocessing of attribute variables and the determination of current branch variables.

(1) Preprocessing of Attribute Variables.

For the variables with fixed attributes, find and merge categories that have no significant effect on the value of the target variable among multiple categories.

For the variables of fixed distance attributes, group by quantile first and then merge groups with homogeneity. If the output variable is a subtype, the chi-squared test is used. If the output variable is a numeric value, the $\mathrm{F}$ test of the analysis of variance is used.

(2) Determining the Current Branch Variable and the Separation Value.

Calculate the statistic and $P$ value of both attribute variable and target variable by the chi-squared test after preprocessing. The variable with the smallest $P$ value is taken as the current best branch variable, and all groups of the variable form the child nodes under the branch.

Repeat the above processing for each node is repeated until the convergence condition is met. 
(3) Main Formula. In the goodness-of-fit test for distribution, the square of the difference between the actual observation number $f_{0}$ and the theoretical (expected) number $C$ divided by the theoretical number approximately subjects to the chi-squared distribution, that is,

$$
X^{2}=\sum \frac{\left(f_{0}-f_{e}\right)^{2}}{f_{e}} \sim X^{2} f_{e} \geq 5
$$

If the difference between the actual number of observations and the theoretical number is greater, the chi-square test result is more likely to reject the null hypothesis and accept the alternative hypothesis. The greater the theoretical number $f_{e}\left(f_{e} \geq 5\right)$, the better the fitting effect.

In the CHAID model, the Pearson chi-square test or the likelihood ratio test (LRT) can be used to classify data. However, when the sample size is small, the Pearson chisquare value should not be used for classification. The calculation formula of the likelihood ratio is as follows:

$$
L R=2 \times\left(\ln L_{1}-\ln L_{2}\right) .
$$

Here, $L R$ is the likelihood ratio. $L_{1}$ is the maximum likelihood value of the complex model. $L_{2}$ is the maximum likelihood value of the simple standard model. $L R$ approximately conforms to the chi-square distribution.

The degree of freedom is used to test the significance of the difference between two models with regard to the likelihood ratio. In the likelihood ratio test, the degree of freedom is equal to the number of additional parameters in the complex model.

It is supposed that the overall sample $X$ subjects to the distribution $P(x ; \theta)$. (When $X$ is a continuous random variable, $P(x ; \theta)$ is the probability density function). The joint distribution function of the samples is the likelihood function.

$$
\begin{aligned}
L(\theta) & =L\left(x_{1}, x_{2}, \ldots, x_{n} ; \theta\right) \\
& =\prod P(x ; \theta) .
\end{aligned}
$$

Here, $\theta$ is the parameter to be estimated.

$X_{1}, X_{2}, \ldots X_{n}$ are all observed values from the overall sample.

Lift is used to reflect the revenue (\%) and the response (\%) in the CHAID model. The higher the lift, the better the characteristics of the model, the stronger its capture ability, and the better the profit of the model currently. The calculation formula of lift is as follows:

$$
\text { lift }=\frac{P\left(\text { class }_{t} / \text { sample }\right)}{P\left(\text { class }_{t} / \text { population }\right)},
$$

where $P\left(\right.$ class $_{t} /$ sample $)$ represents the probability that the output variable value is class $t$ in the specific sample space defined by the model, and $P$ (class $/$ /population) represents the probability that the output variable value is class $t$ in all sample spaces.

\section{Data and Analysis}

\subsection{Data Collection}

4.1.1. Design of the Questionnaire. The survey method was adopted to collect experimental data in this study. The questionnaire was designed based on the risk influence index system and the research methods of this study. All survey items were measured on a five-point Likert scale and are listed in Appendix. Before undertaking this survey, the validity of the questionnaire content was examined to ensure that the questionnaire showed exactly what it was intended to survey. The questionnaire content validity was evaluated using a panel of experts such as potential research subjects and professionals with research experience or who work in the field. The panel feedback helped modify the wording, content validity, and structure of specific questions where necessary [37]. In this research, some experts in the power enterprise and the multistation-related industry were asked for their opinions, and once they validated the questionnaire, amendments were made according to their suggestions.

The target population of this study includes the researchers and technicians from government departments, education and scientific research institutions, power enterprise, and multistation-related companies. The structure of the questionnaire includes five parts: explanatory letter, answer sheet description, background information of the respondent, explanation of the multistation integrated operation risk indicators, and concluding remarks (detailed in Appendix). The content of the questionnaire is divided into two sections. The first section involves the work unit, working years, position, and other information of the respondent. The second one conducts a survey on various indicators, and the indicators are scored using the five-point Likert scale.

4.1.2. Statistical Description. The questionnaire survey lasted for nearly three months (August 2020 to November 2020). In fact, a total of 500 questionnaires were distributed to the target participants, and 416 responses were received, with a recovery rate of $83.2 \%$. There are 343 valid questionnaires, with an effective rate of $82.45 \%$ (detailed in Table 2). We conduct descriptive analysis, reliability analysis, and validity analysis on the sample data collected from the questionnaire.

Reliability test is used to study the reliability and accuracy of answers to quantitative data (especially attitude scale questions). The reliability of the indicators can be measured in two aspects-Cronbach's alpha $(\alpha)$ and corrected item-total correlation (CITC).

It can be seen from Table 3 that Cronbach's $\alpha$ is 0.833 which surpasses the recommended cut-off of 0.80 . It shows that the research data have high-quality reliability. The addition or decrement of the items does not cause a significant change in deleted Cronbach's alpha, and it means that the items should not be deleted. The CITC of the analysis items is all greater than the recommended cut-off of 0.4 . It indicates that the analysis items have a good correlation, and the reliability level is good. Therefore, the reliability of the data has high quality and can be used for further analysis. 
TABle 2: Personal information form of survey respondents, $N=343$.

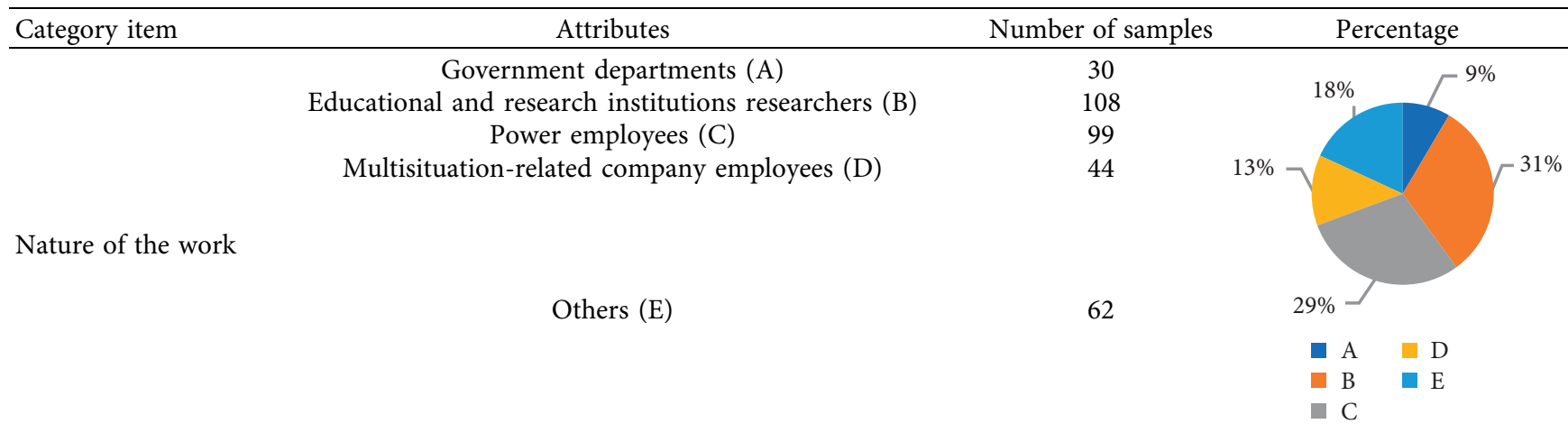

$\begin{array}{cc}\text { PhD (and current students) (A) } & 47 \\ \text { Master (and current students) (B) } & 110 \\ \text { Undergraduate (C) } & 157\end{array}$

Education level

Below bachelor degree (D)

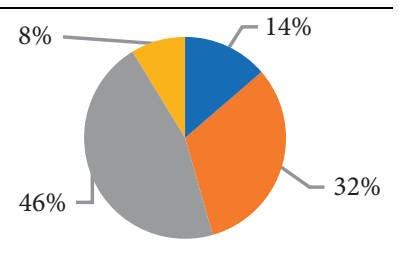

\begin{tabular}{cc} 
& \\
\hline & \\
\hline & 162 \\
$4-10$ years than 3 years $(\mathrm{A})$ & 127 \\
$11-15$ years $(\mathrm{C})$ & 45
\end{tabular}

Working hours

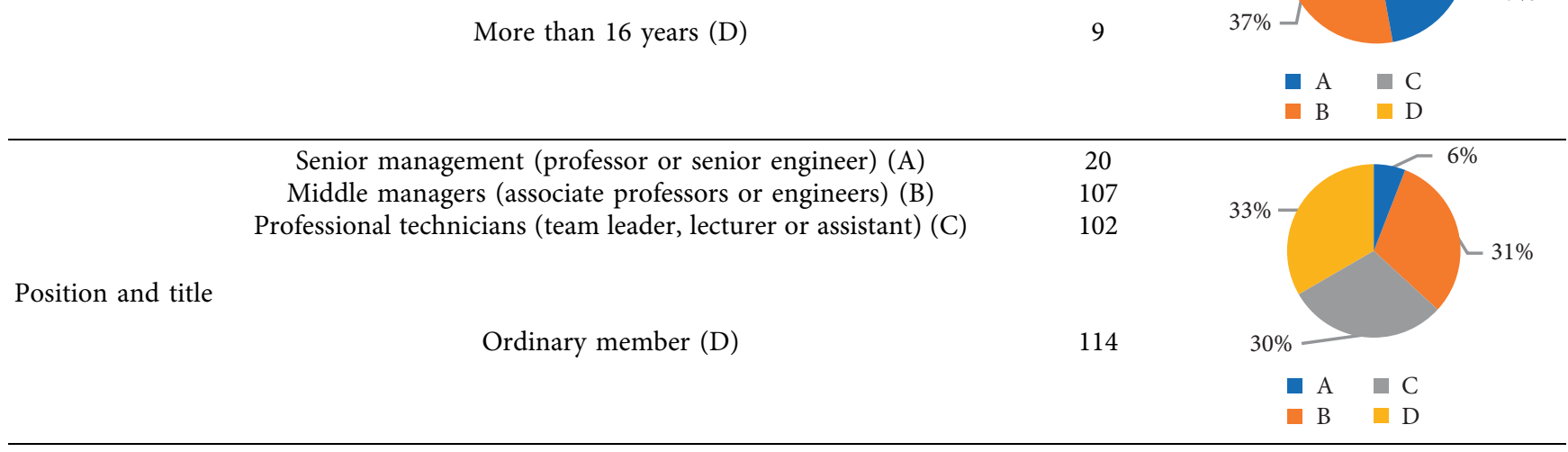

TABLE 3: Reliability results.

\begin{tabular}{|c|c|c|c|}
\hline Indicators & Corrected item-total correlation (CITC) & Deleted Cronbach's alpha & Cronbach's alpha \\
\hline Information risk & 0.497 & 0.820 & \multirow{12}{*}{0.833} \\
\hline Location risk & 0.482 & 0.821 & \\
\hline Technical risk & 0.505 & 0.819 & \\
\hline Cultural risk & 0.478 & 0.822 & \\
\hline Financial risk & 0.532 & 0.817 & \\
\hline Performance risk & 0.560 & 0.815 & \\
\hline Demand risk & 0.487 & 0.821 & \\
\hline Institutional risk & 0.493 & 0.820 & \\
\hline Cyclical risk & 0.542 & 0.816 & \\
\hline Policy risk & 0.537 & 0.816 & \\
\hline Accident risk & 0.470 & 0.823 & \\
\hline Standardized Cror & pha: 0.834 & & \\
\hline
\end{tabular}


After reviewing for reliability, the data are checked for validity. Validity test is used to analyze whether the research item is reasonable and meaningful. Validity analysis requires the Bartlett test (corresponding $p$ value needs to be less than 0.05 ).

It can be seen from Table 4 that the KMO value is 0.893 , the KMO value surpasses the recommended cut-off of 0.80 , and the validity of the research data is well.

\subsection{Data Analysis}

4.2.1. Data Pretreatment. The collected data, organized as aligned matrices, with the 11 categories of risk variables, are submitted to the following pretreatments.

If the total number of cases $\geq 40$ and the minimum theoretical frequency $>5$ (expected count less than 5 ), the chi-square test conditions are met, and the chi-square value (Pearson chi-square) and the corresponding $P$ value (Sig) are selected. If $P \leq 0.05$, the difference is statistically significant. If $P>0.05$, the difference is not statistically significant.

It can be seen from Table 5 that $P=0.000<0.05$, the difference is statistically significant.

The two principal components in Table 6 are defined: principal component 1 is defined as " early stage risk", including "performance risk", "cultural risk", "cyclical risk", "financial risk", "accident risk", "policy risk", and "location risk." "Principal component 2" is defined as "operational risk", including "demand risk", "institutional risk", "information risk", and "technical risk".

According to Table 7 and the decomposition result of the multistation integrated operation risk sources, the multistation integrated operation risk indicators can be decomposed, as shown in Figure 2.

\subsubsection{Construction of SEM}

(1) Measurement Analysis. In this study, the data obtained will be tested using LISREL 8.8 software as part of the structural equation modeling (SEM).

Model evaluation tests its fit degree based on the indicators in the output result of LISREL8.8.

First, before the model evaluation, the estimated parameters in the model results need to be tested for statistical significance. The path coefficients or the load coefficients also need to be tested. The value of $t$ statistic is between 9.34 and 12.42 according to the information provided in LISREL.OUT. It satisfies the general situation. The absolute value of $t$ value is greater than 2 , and the parameter is significantly nonzero (the significance level was 0.05). In other words, the model results are statistically significant.

Second, the degree of fit of the theoretical model to the fitting parameters needs to be checked. Different types of fitting parameters can be used to measure the theoretical model in terms of model complexity, sample size, relativity, and absoluteness, as shown in Table 8 . The fitting parameters all meet the requirements of the recommended values, so the model is reasonable.
(2) Structural Analysis. The influence relationship between the first-order factors is verified to achieve the purpose of structural analysis. The standardized path coefficients of the early stage risk and the operational risk are both 0.78 , as shown in Figure 3. It shows that the endogenous risk and the exogenous risk interact and influence each other.

(3) Model Analysis. The higher-order factor analysis of the multistation integrated operation risks is shown in Figure 4.

The observed results are as follows.

The early stage risk is the most important factor affecting the integrated operation of multistation. Such risk has the highest impact on the multistation integrated risk system with a value of 0.89 . It shows that the early stage risk plays the most important role in the risk management and control of the multistation integrated operation. From the load coefficients of the observed variables, the values of R1, R2, $\mathrm{R} 8$, and $\mathrm{R} 9$ are $0.55,0.59,0.56$, and 0.48 , respectively. In general, the load coefficients need to be greater than 0.5 , and R9 does not meet the requirement. And it will not be removed considering its economic and practical significance.

The operational risk is the secondary main influence factor affecting the integrated operation of multistation. Its path coefficient is 0.88 . It indicates that the operational risk plays an important role in the management and control of the multistation integrated operational risk. From the point of the load coefficients, the values of R3, R4, R5, R6, R7, R10, $\mathrm{R} 11$ are $0.55,0.60,0.55,0.62,0.57,0.55,0.58$, respectively. The above shows that the cultural risk (R6) and the performance risk (R4) are the important risk indicators in the operational risk.

(4) Model Measurement. The path coefficient is essential to show the relationship between the observed variable and the latent variable in this model. However, it can only get the degree of influence between the variables and cannot quantify the influence coefficient. Therefore, it is necessary to build a weight measurement model to quantify the degree of influence among variables.

The above-mentioned load coefficients are normalized by mathematical methods to obtain the weight coefficient of each variable. The calculation process is as follows:

$$
\begin{aligned}
\rho_{i j} & =\frac{\lambda_{i j}}{\sum_{j=1}^{n} \lambda_{i j}}, \\
\psi & =\sum_{i=1}^{2} \beta_{i} \sum_{j=1}^{N} \rho_{i j} \cdot R_{i j} .
\end{aligned}
$$

The content of Figure 5 is processed to obtain the weight coefficients of the variables in the multistation integrated operation risk coefficient evaluation model, as shown in Table 9.

The weight coefficients represent the significance of risks. Based on the obtained values, we can see the impact of considered risks within the project. In the next step, the weight of each risk was used to calculate the global weighting values of the multistation integrated operation risk evaluation model. 
TABLe 4: Validity analysis.

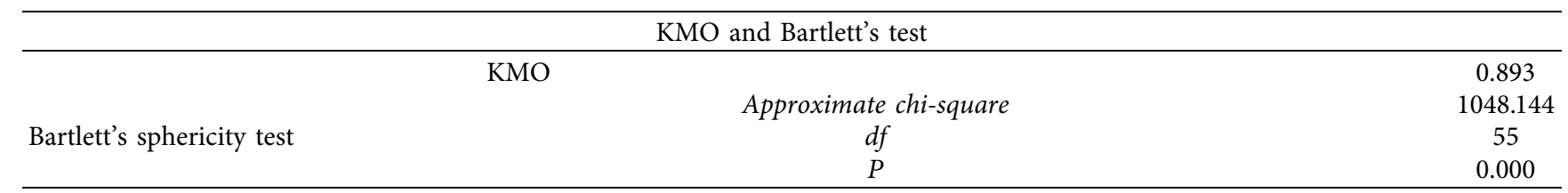

TABLE 5: Chi-square test statistics.

\begin{tabular}{|c|c|c|c|}
\hline Risk variables & Chi-square & Degree of freedom & Asymptotic significance \\
\hline Information risk & $283.778^{\mathrm{a}}$ & 4 & 0.000 \\
\hline Technical risk & $205.557^{\mathrm{a}}$ & 4 & 0.000 \\
\hline Performance risk & $180.717^{\mathrm{a}}$ & 4 & 0.000 \\
\hline Cultural risk & $94.536^{\mathrm{a}}$ & 4 & 0.000 \\
\hline Location risk & $166.344^{\mathrm{a}}$ & 4 & 0.000 \\
\hline Financial risk & $183.691^{\mathrm{a}}$ & 4 & 0.000 \\
\hline Cyclical risk & $187.073^{\mathrm{a}}$ & 4 & 0.000 \\
\hline Institutional risk & $230.134^{\mathrm{a}}$ & 4 & 0.000 \\
\hline Demand risk & $184.099^{\mathrm{a}}$ & 4 & 0.000 \\
\hline Policy risk & $194.420^{\mathrm{a}}$ & 4 & 0.000 \\
\hline Accident risk & $114.507^{\mathrm{a}}$ & 4 & 0.000 \\
\hline
\end{tabular}

TABle 6: Component matrix after rotation.

\begin{tabular}{lcc}
\hline Risk variables & Principal component 1 & Principal component 2 \\
\hline Information risk & 0.176 & 0.786 \\
Technical risk & 0.159 & 0.803 \\
Location risk & 0.592 & 0.215 \\
Performance risk & 0.657 & 0.238 \\
Financial risk & 0.635 & 0.189 \\
Cultural risk & 0.652 & 0.131 \\
Cyclical risk & 0.652 & 0.203 \\
Institutional risk & 0.289 & 0.656 \\
Demand risk & 0.444 & 0.391 \\
Policy risk & 0.610 & 0.235 \\
Accident risk & 0.623 & 0.108 \\
\hline
\end{tabular}

TABLE 7: Multisituation integrated operation risk index variable decomposition.

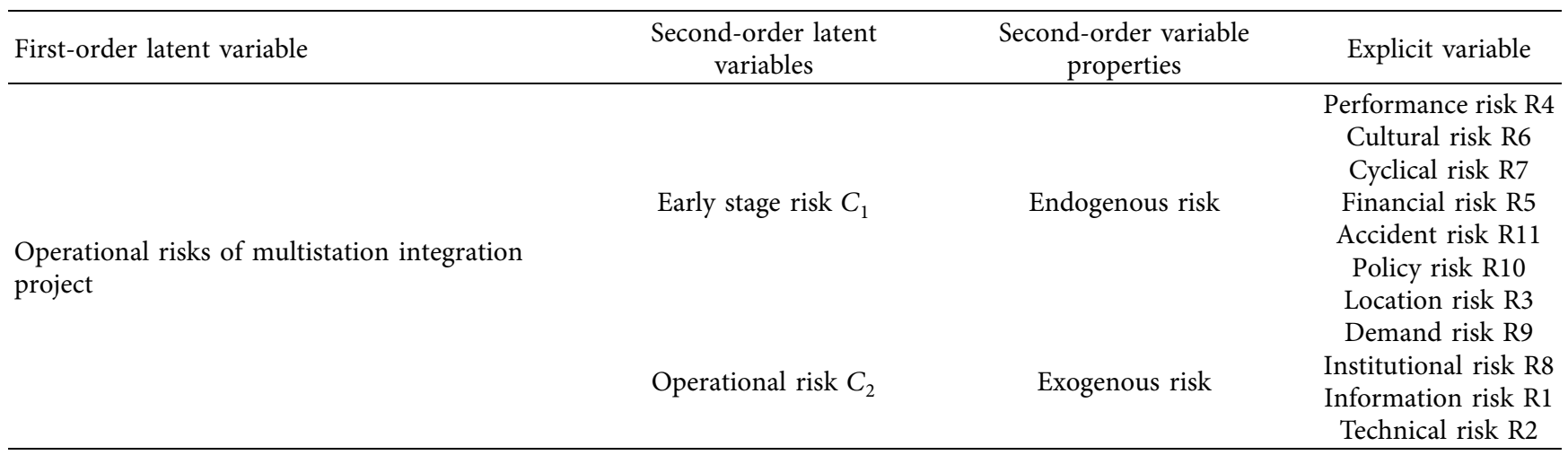




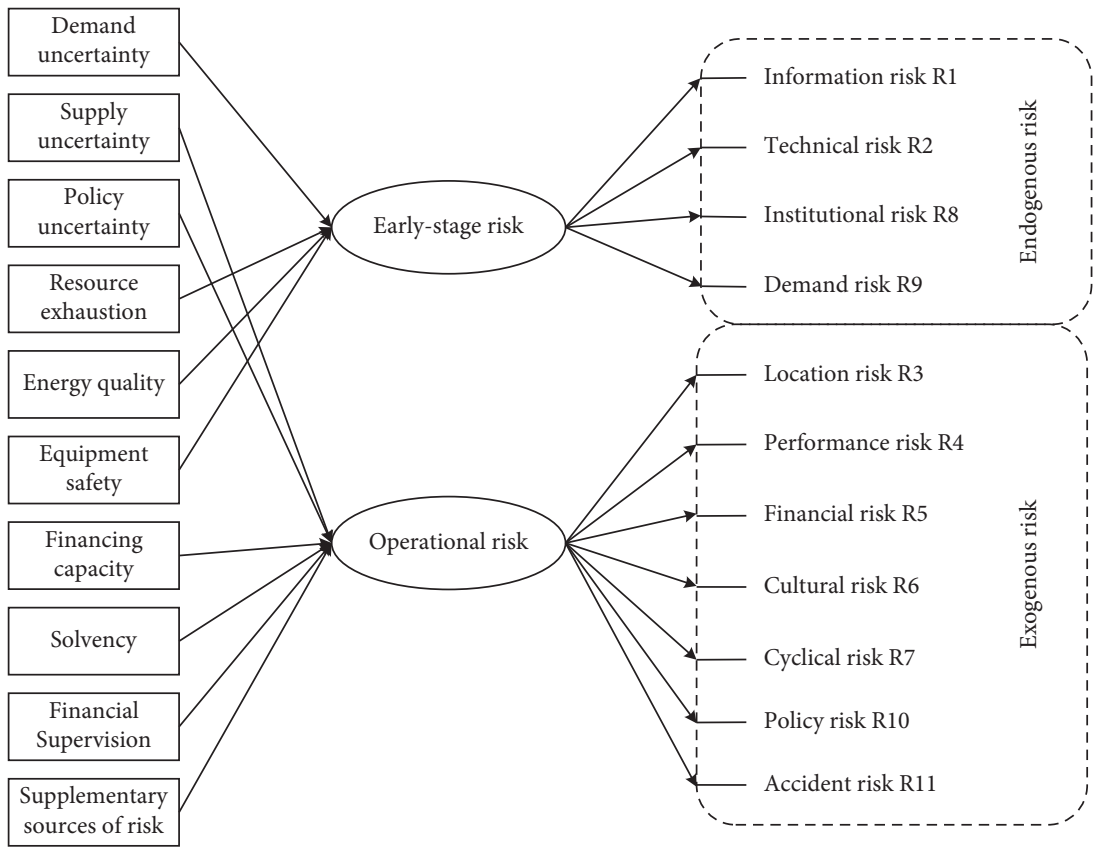

FIGURE 2: Decomposition of risk indicators for multistation integrated operation.

TABLE 8: Recommended values of the fitting parameters and the actual test results.

\begin{tabular}{lccccccc}
\hline$X^{2} / \mathrm{df}$ & GFI & AGFI & NFI & IFI & CFI & RMSEA & $P$ value \\
\hline$<5$ & $>0.9$ & $>0.9$ & $>0.9$ & $>0.9$ & $>0.9$ & $<0.08$ \\
2.098 & 0.95 & 0.93 & 0.95 & 0.98 & 0.98 & 0.057 & 0.14 \\
\hline
\end{tabular}

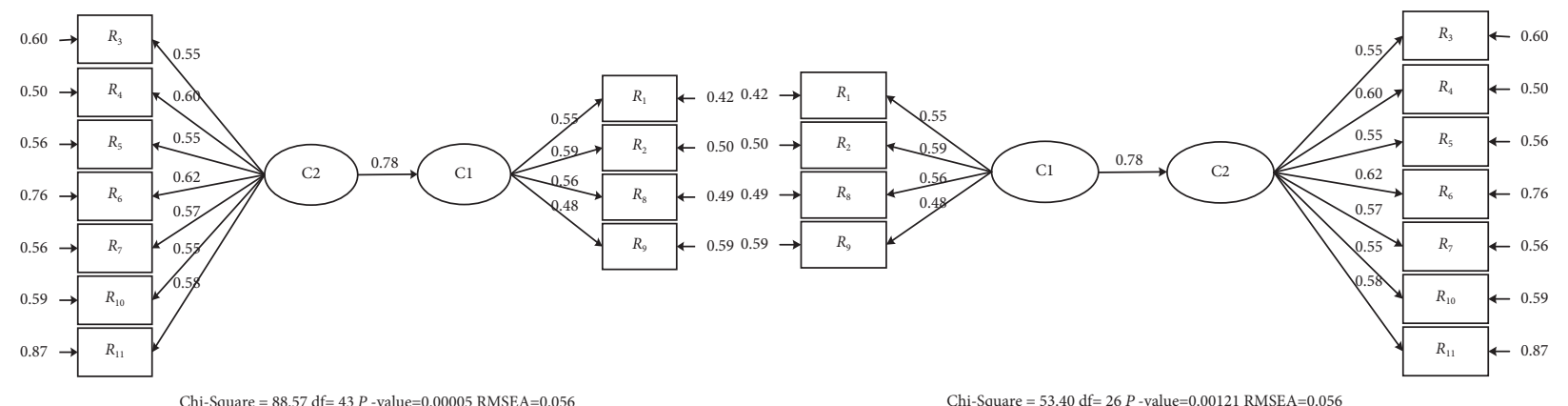

FIGURE 3: Structural relationship between the early stage risk and the operational risk.

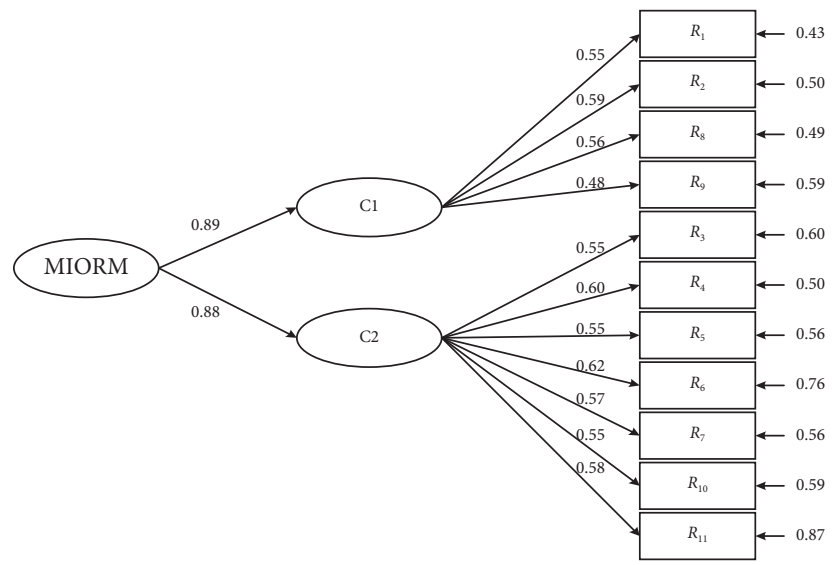

FIGURE 4: Standardized road map of multistation integrated operation risk evaluation model. 


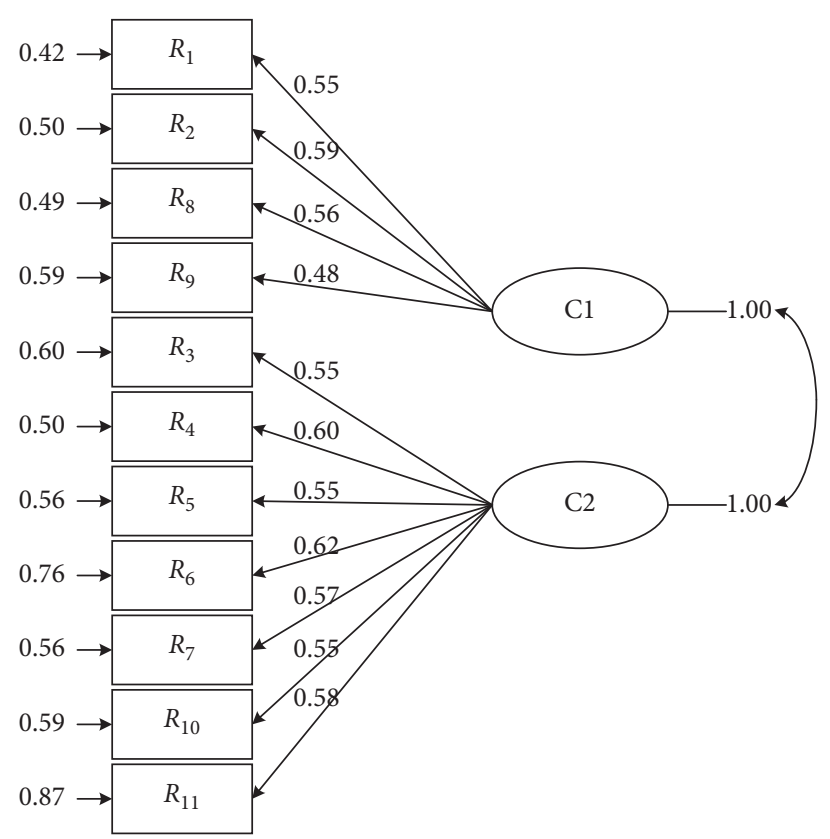

FIGURE 5: Latent variable and observed variable factor loading.

TABLE 9: Weight coefficients of the multistation integrated operation risk evaluation model.

\begin{tabular}{|c|c|c|c|c|}
\hline First-order indicator & Weights & Second-order indicator & Weights & Third-order indicator \\
\hline \multirow{11}{*}{ Risk coefficient of multistation integration project } & \multirow{4}{*}{50.28} & \multirow{5}{*}{ Early stage risk (C2) } & 25.23 & Information risk (R1) \\
\hline & & & 27.06 & Technical risk (R2) \\
\hline & & & 25.69 & Institutional risk (R8) \\
\hline & & & 22.02 & Demand risk (R9 ) \\
\hline & \multirow{7}{*}{49.72} & & 13.68 & Location risk (R3) \\
\hline & & \multirow{6}{*}{ Operational risk $(\mathrm{C} 1)$} & 14.93 & Performance risk (R4) \\
\hline & & & 13.68 & Financial risk (R5) \\
\hline & & & 15.42 & Cultural risk (R6) \\
\hline & & & 14.18 & Cyclical risk (R7) \\
\hline & & & 13.68 & Policy risk (R10) \\
\hline & & & 14.43 & Accident risk (R11) \\
\hline
\end{tabular}

$$
\begin{aligned}
\text { index }(\text { MIORM })= & 0.12685644 \cdot R_{1}+0.13605768 \cdot R_{2} \\
& +0.12916932 \cdot R_{8}+0.11071656 \cdot R_{9} \\
& +0.06801696 \cdot R_{3}+0.07423196 \cdot R_{4} \\
& +0.06801696 \cdot R_{5}+0.07666824 \cdot R_{6} \\
& +0.07050296 \cdot R_{7}+0.06801696 \cdot R_{10} \\
& +0.07174596 \cdot R_{11} .
\end{aligned}
$$

Formula (6) is the final form of the multistation integration risk measurement model.

The main risk factors of the multistation integrated operation system are the technical risk, the institutional risk, the information risk, and the demand risk, followed by the location risk, the performance risk, the financial risk, the cultural risk, the cyclical risk, the policy risk, and the accidental risk. The key points of the risk aversion can be clarified according to the weight coefficient in the management and control of the multistation integrated operation. And in this way, its risk is minimized.

\subsubsection{Construction of CHAID}

(1) Model Establishment and Execution Results. This paper intends to use Clementine 12.0 to complete the classification modeling process.

The data into the data stream are imported and selected "classification" to preprocess the data:

CHAID in "modeling" is selected and added it to the data stream.

In the option of "field", the system default initial settings are kept.

In the option of "expert", "expert" for the mode item is selected, "likelihood ratio" for the chi-square category target is selected, and the system defaults for other options are kept.

Both "cost" and "comment" remain unchanged.

The model execution result is shown in Figure 6:

CHAID presents a multibranch structure. Figure 6 shows the CHAID decision tree, and the risk profiles 


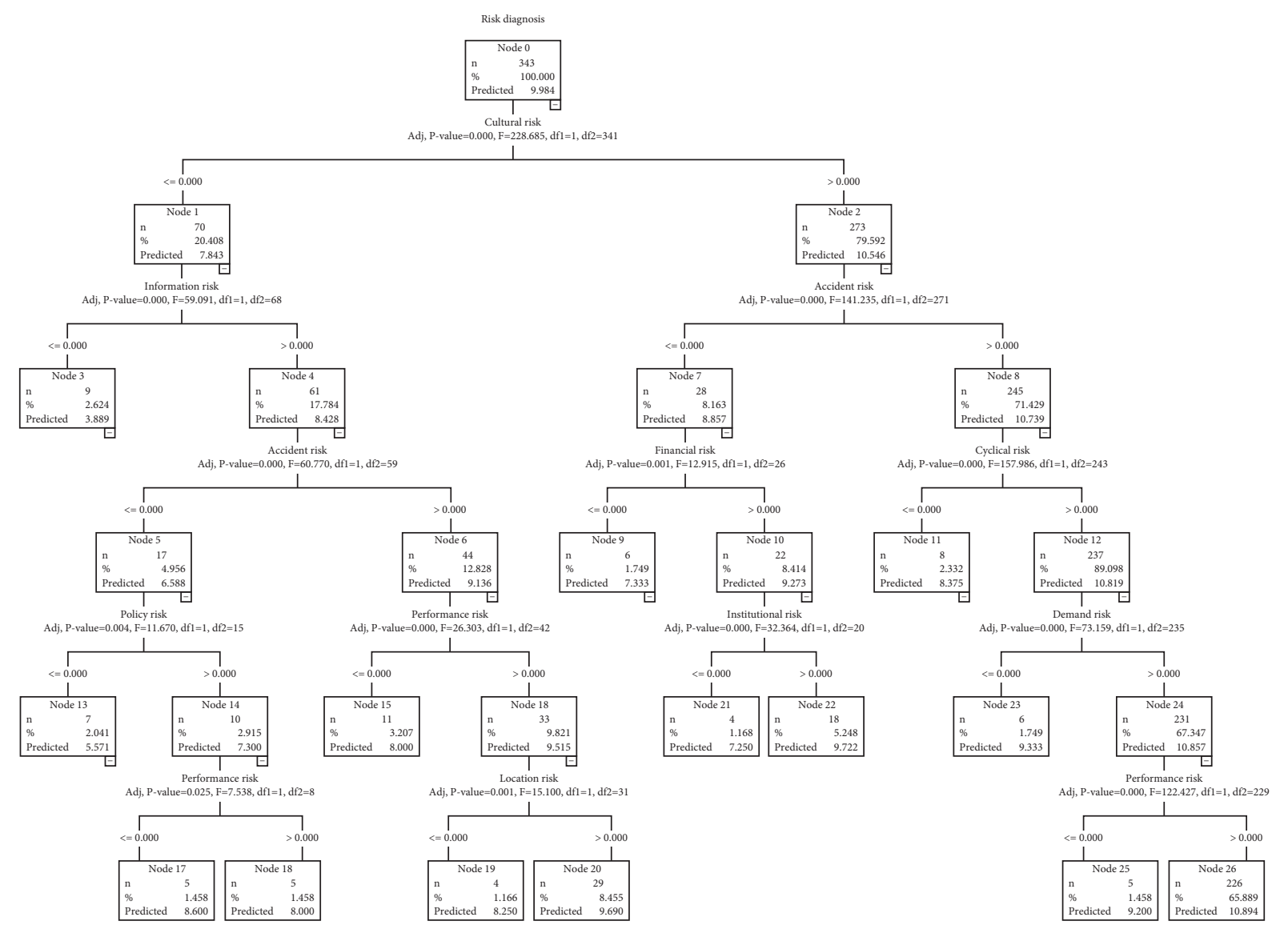

Figure 6: The decision tree and the degree of the multisituation integrated operation risk.

obtained by the CHAID algorithm. The risk evaluation process of the multistation integrated operation is based on risk diagnosis and has a strong correlation $(P<0.001)$. When there has no cultural risk, decision makers should give priority to the information risk in the operational risk system ( $N=70$ accounting for $20.408 \%$ of the total sample). When there has the cultural risk, decision makers should give priority to the accidental risk in the operational risk system $(N=273$ accounting for $79.592 \%$ of the total sample). The decision-making process for other risks can be deduced by analogy.

As can be seen from Figure 6, the risk profiles can be divided into 14 categories. The algorithm can classify a large amount of data into 14 different risk profiles, although CHAID can only classify the risk of the multistation integration operation into "risk" (1) and "no risk" (0). It can be seen from Table 10 that CHAID screens out ten risk indicators affecting the safety of the multistation integrated operation (The technical risk will not be excluded in consideration of its practical significance). As a result, decision makers can choose the management focus of risk indicators to both improve the risk profiles and enhance the safety of the operating system.

(2) Evaluation of Model Benefits. In Tables 11 and 12, the profit evaluation data of the model can be obtained.
"Node: $n$ " indicates the number of nodes in the sample.

"Node (\%)" indicates the percentage of the number of nodes in the total number of samples.

"Index (\%)" indicates the degree of improvement. The larger the value of the "Index (\%)", the better the benefits of the model.

In addition, from the model of CHAID, the error rate of the decision tree is 0.355 , and the standard error is 0.072 . It shows that the risk evolution analysis process is scientific and reasonable.

From the branch destination of the risk decision tree, "cultural risk", "information risk", and "accidental risk" belong to external risk, and "performance risk" and "location risk" belong to internal risk.

First, decision makers should judge whether there is a "cultural risk" at the surface level. If there is, they give priority to "information risk"; otherwise, they consider "accident risk".

Second, decision makers consider whether there are "information risk" and "accident risk" at the second level of risks.

Third, decision makers consider "financial risk" and "cyclical risk" at the third level of risks, until decision makers consider risk indicators involving the lowest level so that they can provide effective and economic risk aversion plans based on the priority of all risks. 
TABLE 10: Risk profiles of multistation integration.

\begin{tabular}{|c|c|c|c|c|c|c|c|c|c|c|c|}
\hline \multirow{2}{*}{ Risk profiles } & \multirow{2}{*}{ Node } & \multicolumn{10}{|c|}{ Risk indicators } \\
\hline & & R6 & $\mathrm{R} 1$ & R11 & $\mathrm{R} 10$ & $\mathrm{R} 4$ & R3 & R5 & $\mathrm{R} 8$ & R7 & R9 \\
\hline 1 & $0,1,3$ & $\leq 0$ & $\leq 0$ & & & & & & & & \\
\hline 2 & $0,1,4,9,23$ & $\leq 0$ & $>0$ & $\leq 0$ & $\leq 0$ & & & & & & \\
\hline 3 & $0,1,4,9,24,25$ & $\leq 0$ & $>0$ & $\leq 0$ & $>0$ & $\leq 0$ & & & & & \\
\hline 4 & $0,1,4,9,24,26$ & $\leq 0$ & $>0$ & $\leq 0$ & $>0$ & & $>0$ & & & & \\
\hline 5 & $0,1,4,10,21$ & $\leq 0$ & $>0$ & $>0$ & $>0$ & $\leq 0$ & & & & & \\
\hline 6 & $0,1,4,10,22,27$ & $\leq 0$ & $>0$ & $>0$ & $>0$ & $>0$ & $\leq 0$ & & & & \\
\hline 7 & $0,1,4,10,22,28$ & $\leq 0$ & $>0$ & $>0$ & $>0$ & $>0$ & $>0$ & & & & \\
\hline 8 & $0,2,5,7$ & $>0$ & & $\leq 0$ & & & & $\leq 0$ & & & \\
\hline 9 & $0,2,5,8,19$ & $>0$ & & $\leq 0$ & & & & $>0$ & $\leq 0$ & & \\
\hline 10 & $0,2,5,8,20$ & $>0$ & & $\leq 0$ & & & & $>0$ & $>0$ & & \\
\hline 11 & $0,2,8,11$ & $>0$ & & $>0$ & & & & & & $\leq 0$ & \\
\hline 12 & $0,2,8,12,13$ & $>0$ & & $>0$ & & & & & & $>0$ & $\leq 0$ \\
\hline 13 & $0,2,8,12,14,15$ & $>0$ & & $>0$ & & $\leq 0$ & & & & $>0$ & $>0$ \\
\hline 14 & $0,2,8,12,14,16$ & $>0$ & & $>0$ & & $>0$ & & & & $>0$ & $>0$ \\
\hline
\end{tabular}

TABLE 11: Revenue data of each node in the training sample.

\begin{tabular}{lcccc}
\hline Node & Node: $\mathrm{n}$ & Node $(\%)$ & Mean & Index $(\%)$ \\
\hline 16 & 226.00 & 65.89 & 10.89 & 109.00 \\
20 & 18.00 & 5.25 & 9.72 & 97.28 \\
28 & 29.00 & 8.45 & 9.69 & 96.95 \\
13 & 6.00 & 1.75 & 9.33 & 93.39 \\
15 & 5.00 & 1.46 & 9.20 & 92.05 \\
11 & 8.00 & 2.33 & 8.38 & 83.80 \\
27 & 4.00 & 1.17 & 8.25 & 80.55 \\
21 & 11.00 & 3.21 & 8.00 & 80.05 \\
26 & 5.00 & 1.46 & 8.00 & 73.38 \\
7 & 6.00 & 1.75 & 7.33 & 72.54 \\
19 & 4.00 & 1.17 & 7.25 & 6.05 \\
25 & 5.00 & 1.46 & 5.04 & 55.75 \\
23 & 7.00 & 2.04 & 5.57 & 38.91 \\
3
\end{tabular}

TABLE 12: Cumulative revenue data in training samples.

\begin{tabular}{lcccc}
\hline Node & Node: $n$ & Node (\%) & Mean & Index (\%) \\
\hline 16 & 226 & 65.89 & 10.89 & 109.00 \\
20 & 244 & 71.14 & 10.81 & 10.69 \\
28 & 273 & 79.59 & 10.66 & 106.95 \\
13 & 279 & 81.34 & 10.63 & 106.66 \\
15 & 284 & 82.80 & 10.57 & 106.40 \\
11 & 292 & 85.13 & 10.54 & 105.78 \\
27 & 296 & 86.30 & 10.45 & 104.56 \\
21 & 307 & 89.50 & 10.41 & 104.16 \\
26 & 312 & 90.96 & 10.35 & 103.58 \\
7 & 318 & 92.71 & 10.31 & 103.20 \\
19 & 322 & 93.88 & 10.26 & 102.63 \\
25 & 327 & 95.34 & 10.16 & 101.65 \\
23 & 334 & 97.38 & 9.99 & 100.00 \\
3
\end{tabular}


TABLE 13: The importance of risk indicators for multisituation integration project.

\begin{tabular}{|c|c|c|c|}
\hline \multirow{2}{*}{$\begin{array}{l}\text { Risk indicators } \\
\text { Information risk R1 }\end{array}$} & \multicolumn{3}{|c|}{ The importance of risk (the number size indicates the degree) } \\
\hline & 2 & 3 & 4 \\
\hline \multicolumn{4}{|c|}{$\begin{array}{l}\text { Explanation: the requirements for real-time monitoring and feedback in the multistation integration are higher than before, and there are } \\
\text { many opportunities for information errors in the information transmission. }\end{array}$} \\
\hline Technical risk R2 & 1 & 3 & 4 \\
\hline \multicolumn{4}{|c|}{$\begin{array}{l}\text { Explanation: the advancement, reliability, practicability, and availability of technology have undergone major changes with the expected } \\
\text { plan. It does not achieve the expected results and leads to the risk of loss. }\end{array}$} \\
\hline Location risk $\mathrm{R} 3$ & 1 & 3 & 4 \\
\hline \multicolumn{4}{|c|}{ Explanation: the location limitation of some stations is prominent. It is difficult to control due to the influence of regional factors. } \\
\hline Performance risk $\mathrm{R} 4$ & 1 & 3 & 4 \\
\hline \multicolumn{4}{|c|}{ Explanation: the project schedule deviation causes the risk of loss. } \\
\hline Financial risk $\mathrm{R} 5$ & 1 & 3 & 4 \\
\hline \multicolumn{4}{|c|}{ Explanation: the risk comes from changes in the project profit margin and the tax rate. } \\
\hline Cultural risk R6 & 1 & 3 & 4 \\
\hline \multicolumn{4}{|c|}{ Explanation: the possibility of conflict increases in the original operation mode, the operation concept, and the system integration. } \\
\hline Cyclical risk $\mathrm{R} 7$ & $1 \quad 2$ & 3 & 4 \\
\hline \multicolumn{4}{|c|}{ Explanation: it is necessary to pay attention to the problem of mismatch between investment and income. } \\
\hline Institutional risk R8 & 1 & 3 & 4 \\
\hline \multicolumn{4}{|c|}{ Explanation: there is a certain conflict between the industry development environment and the multistation integration scenario. } \\
\hline Demand risk R9 & 1 & 3 & 4 \\
\hline \multicolumn{4}{|c|}{$\begin{array}{l}\text { Explanation: the diversification of multisite converged services is more uncertain than the single business. And the market demand } \\
\text { indicators have changed. }\end{array}$} \\
\hline Policy risk R10 & 12 & 3 & 4 \\
\hline \multicolumn{4}{|c|}{ Explanation: there are uncertainties in the adjustment and revision of the regulations, the systems, and the laws. } \\
\hline Accident risk R11 & $1 \quad 2$ & 3 & 4 \\
\hline \multirow{2}{*}{\multicolumn{4}{|c|}{$\begin{array}{l}\text { Explanation: the damage caused by earthquakes, fires, public health security, political turmoil, unexpected wars, climate change and } \\
\text { environmental degradation, etc. }\end{array}$}} \\
\hline & & & \\
\hline & 1 & 3 & 4 \\
\hline
\end{tabular}

\section{Conclusion and Policy Implication}

5.1. Conclusions. The analysis based on the multistation integration project to evaluate operational risk is presented in this article. The scheme can provide the reference of risk aversion, which is not taken into account in the conventional method.

First, the evaluation analysis of the multistation integrated operation risk can be divided into the structural analysis and the procedural analysis. The structural analysis mainly reflects the structural relationship between various risks, which can be used in theory to determine the transmission path and hierarchical relationship of risks. The procedural analysis mainly reflects the priority and focus of risks in the decision-making process.

Second, risk indicators of the multistation integrated operation are divided into two major categories using the structural equation modeling. The main risk sources of MSI come from the internal risk, followed by the external risk. The 11 risk indicators influence and interact with each other through different paths and methods, and then, "technical risk" is the most important one.

Third, the risk profiles of the multistation integrated operation are divided into 14 categories using the data mining model. In the decision-making process, the decision maker should determine whether there is "cultural risk" first. In this case, the "information risk" should be given priority; otherwise, the "accidental risk" should be considered. Then, they consider the third level of "financial risk" and "cyclical risk", until they consider the lowest level of risk indicators. The analysis of the risk process is conducive to the early warning and control of operational risks for decision makers.

The limitation of our work is that the research is based on the subjective data. Consequently, future research should include more practical cases data from different settings. In addition, risk management and control measures should be formulated according to the risk profile of each case.

5.2. Policy Implications. Currently, the multistation integration project is emerging as a new focus of the national energy strategy. China urgently needs to solve the problem of its safe and stable operation. Therefore, we offer the following suggestions:

It is necessary to effectively promote the multistation integration pilot operation and improve the institutional. As a result, deadly risk factors can be avoided in the station selection and construction, and operational safety can be achieved in terms of cost, investment, and scale.

It is indispensable to deepen the research on the risk theoretical system with Chinese characteristics based on the multistation integrated management. This theoretical system will become a strong support and an effective mechanism for the management and control of the multistation integrated risk.

It is crucial for promoting technological innovation and making full use of the leading role of the power enterprise in the multistation integrated operation project. In this way, a 
standardized, stable, and safe operating environment is formed to promote the development of MSI.

\section{Abbreviations}

MSI: $\quad$ Multistation integration

SEM: $\quad$ Structural equation model

CHAID: Chi-squared automatic interaction detection

EVA: $\quad$ Economic value adds

VDT: Value driver tree

RAPM: Risk-adjusted performance indicator

NOPAT: Net operating profit after tax

WACC: Weighted average cost of capital

$X^{2} / \mathrm{df}$ : Chi-square/ degrees freedom

GFI: $\quad$ Goodness-of-fit index

AGFI: Adjusted goodness-of-fit index

NFI: $\quad$ Normed fit index

IFI: Incremental fit index

CFI: $\quad$ Comparative fit index

RMSEA: Root mean square error of approximation

$P$ value: Probability.

Parameters and variables

$X$ : Exogenous observation index

$\Lambda_{X}$ : The relationship between $X$ index and latent variable

$\varepsilon: \quad$ The measurement error of $X$

$Y$ : Endogenous observation index

$\Lambda_{Y}$ : The relationship between $Y$ index and $\eta$ latent variable

$\delta$ : $\quad$ The measurement error of $Y$

$\xi$ : $\quad$ Exogenous latent variable

$\Gamma$ : The relationship between exogenous latent variables

$\eta$ : Endogenous latent variable

$B$ : The relationship between endogenous latent variable

$\zeta$ : The unfinished part between variables and variables in the model

$\rho_{i j}$ : The weight proportion of $C_{i}$

$\lambda_{i j}$ : The normalized load coefficients

$\psi$ : The multistation integrated operation risk coefficient

$\beta_{i}$ : The weight coefficient corresponding to the secondary indicators

$R_{i j}$ : The value of the three-level indicators

$N$ : The number of the secondary indicators, $N=1,2$.

\section{Appendix}

\section{A. Questionnaire on Risk Management of Multistation Integration Project}

Respondent background information:

(1) The nature of your work:

Government department

Educational and research institutions researchers

Power employees

Multistation-related company employees

Others

(2) Your education situation:

Ph.D. (and current students)

Master (and current students)
Undergraduate

Below bachelor's degree

(3) Time for you to engage in the multistation integrated operation and the power industry practical work or research:

$$
\begin{aligned}
& \text { Less than } 3 \text { years } \\
& 4-10 \text { years } \\
& 11-15 \text { years } \\
& \text { More than } 16 \text { years }
\end{aligned}
$$

(4) Your current position:

Senior management (professor or senior engineer)
Middle managers (associate professors or
engineers)
Professional technicians (team leader, lecturer, or
assistant)
Ordinary member

\section{B. Explanation of the Answer Sheet}

The risk management of the multistation integration project involves the coordinated development of risk sources, such as electric vehicle charging and swapping station, 5G base station, data center, photovoltaic (PV) power station. The risk is qualitatively divided into 11 indicators (Table 13).

\section{Data Availability}

The experimental data used to support the findings of this study are available from the corresponding author upon request.

\section{Conflicts of Interest}

The authors declare that they have no conflicts of interest.

\section{Acknowledgments}

This work was supported by the National Natural Science Foundation of China (Grant no. 72103128) and the Key Projects in Soft Science Research of Shanghai Science and Technology Commission (Grant no. 21692109400).

\section{References}

[1] X. Zhou and J. Liu, "Research on power supply reliability of AC/DC micro-grid system in "multi-station fusion project," J. Journal of Physics: Conference Series, vol. 1585, Article ID 012024, 2020

[2] W. B. Huang, H. F. Cheng, Z. H. Bai, C. H. Miao, and F. C. Sun, "Optimal design and operation of energy storage power station under multi-station fusion mode," Journal of Distribution \& Utilization, vol. 36, no. 11, pp. 84-91, 2019.

[3] C. H. Yu and S. T. Xu, "Research on data fusion method for multi-station telemetry data processing," Journal of Telemetry, Tracking and Command, vol. 39, no. 1, pp. 47-52+56, 2018.

[4] Y. Huang, C. Y. Zhang, and T. M. Liu, "A probe into the "three stations in one" model of the ubiquitous power internet of things," Journal of Internet of Things Technologies, vol. 10, no. 1, pp. 44-47, 2020. 
[5] H. Ma and J. B. Xu, "Current situation of integrated energy service and suggestions for power grid enterprise business development," J. Power \& Energy, vol. 41, no. 5, pp. 618-622, 2020.

[6] J. X. Hou, Y. Lv, Z. H. Yu, C. Xie, S. Dongyu, and L. Guangming, "Research on real power grid security and stability based on big data analysis method and online data of power grid," in Proceedings of the International Conference on Powet Syastem, pp. 4468-4473, Singapore, February 2018.

[7] Q. Q. Liu, P. K. Liu, Y. Sun, and C. Zhang, "Screening mechanism for priority business of multi-station integration project based on random forest algorithm," Journal of Smart Power, vol. 49, no. 6, pp. 32-39, 2021.

[8] X. Han, Z. Wang, Y. He, Y. Zhao, C. Zhaoxing, and Z. Di, “A mission reliability-driven manufacturing system health state evaluation method based on fusion of operational data," Journal of Sensors, vol. 19, no. 3, p. 422, 2019.

[9] B. J. Li and Y. J. Fang, "Review on online operational security risk assessment of power systems," J. Automation of Electric Power Systems, vol. 36, no. 18, pp. 171-177, 2012.

[10] A. A. Zhang and G. Q. Peng, "Risk assessment of offshore micro integrated energy system based on matter-energy flow analysis," Journal of Automation of Electric Power Systems, vol. 44 , no. 24 , pp. $60-67,2020$.

[11] H. Liu, Y. Li, Y. Cao, Z. Zhilong, and N. V. Denis, "Operational risk assessment of electric-gas integrated energy systems considering N-1 accidents," J. Energies, vol. 13, no. 5, p. 1208, 2020.

[12] X. Yang, S. Haugen, and N. Paltrinieri, "Clarifying the concept of operational risk assessment in the oil and gas industry," J. Safety Science, vol. 108, pp. 259-268, 2018.

[13] L. R. Chen and L. Liu, "Risk assessment and early warning of distribution network operation considering multiple risk factors," A, vol. 14, no. 16, pp. 3139-3129, 2020.

[14] P. Vilela, S. H. Park, and S. Hwangpo, "Optimal utility supply network under demand uncertainty for operational risk assessment on a petrochemical industrial park," Journal of Korean Journal of Chemical Engineering, vol. 37, no. 7, pp. 1116-1129, 2020.

[15] L. Y. Tao and J. H. He, "Operational risk assessment of distribution network with consideration of PV output uncertainties," in Proceedings of the C. China International Conference on Electricity Distribution (CICED 2016), Xi'an, China, August 2016.

[16] Z. F. Tan and P. K. Liu, "Research on risk sources transitive relation of coal - electricity supply chain and risk evaluation in China," J. Journal of Industrial Technological Economics, vol. 34, no. 1, pp. 132-144, 2015.

[17] S. J. Park, C. W. Lee, and S. Lee, "Landslide susceptibility mapping and Comparison using decision tree models: a case study of jumunjin area, korea," Journl of Remote Sensing, vol. 10, no. 10, 2018

[18] H. Su and E. Zio, "A systematic method for the analysis of energy supply reliability in complex Integrated Energy Systems considering uncertainties of renewable energies, demands and operations," J. Journal of Cleaner Production, vol. 267, Article ID 122117, 2020.

[19] D. Wang and Z. G. Meng, "Research and prospect of key technologies for energy interconnection system planning for new-type towns," Journal ofAutomation of Electric Power Systems, vol. 43, no. 14, pp. 16-28, 2019, in Chinese.

[20] T. Zhou, M. Modarres, and E. L. Droguett, "Multi-unit nuclear power plant probabilistic risk assessment: a comprehensive survey," J. Reliability Engineering \& System Safety, vol. 213, Article ID 107782, 2021.

[21] F. H. Moghimi and T. Barforoushi, "Optimal scheduling of resources for a price-maker distribution company in electricity markets considering network component failures," Journal of International Journal of Electrical Power \& Energy Systems, vol. 122, Article ID 106200, 2020.

[22] H. Xiao, W. Pei, W. Deng, T. Ma, S. Zhang, and L. Kong, "Enhancing risk control ability of distribution network for improved renewable energy integration through flexible DC interconnection," Journal of Applied Energy, vol. 284, Article ID 116387, 2021.

[23] T. Wyeld and M. Nakayama, "The structural equation model diagram as a visualisation tool," in Proceedings of the C. $23 R D$ International Conference in Information - PT II (IV-2 2019), pp. 78-81, July 2019, Adelaide, Australia.

[24] H. K. Andersen, "A closer look at random and fixed effects panel regression in structural equation modeling using lavaan," Journal of Structural Equation moeling a Multidisplinary, 2021.

[25] E. Burghgraeve, J. De Neve, and Y. Rosseel, "Estimating Structural Equvation Models Using James-Stein type shrinkage estimators," Journal of PSYCHOMETRIKA, vol. 86, no. 2, p. 668, 2021.

[26] J. Leprince, C. Miller, and W. Zeiler, "Data mining cubes for buildings, a generic framework for multidimensional analytics of building performance data," J. Energy and Buildings, vol. 248, Article ID 111195, 2021.

[27] J. Bridge, S. Kendzierskyj, J. McCarthy, and H. Jahankhani, "Commodification of consumer privacy and the risk of data mining exposure," Journal of Academic Press, vol. 17, pp. 361-380, 2021.

[28] Q. Zhou, X. Li, and J. Liao, "Power failure risk assessment and management based on stochastic line failures in distribution network including distributed generation," Journal of IEEJ Transactions on Electrical and Electronic Engineering, vol. 13, no. 9, pp. 1303-1312, 2018.

[29] M. P. Bach, K. Dumičić, and B. Žmuk, "Internal fraud in a project-based organization: CHAID decision tree analysis," Journal of Procedia Computer Science, vol. 138, pp. 680-687, 2018.

[30] I. Abdin, Y.-F. Li, and E. Zio, "Risk assessment of power transmission network failures in a uniform pricing electricity market environment," Journal of Energy, vol. 138, pp. 10421055, 2017.

[31] N. Ozgulbas and Koyuncugil, "'Risk classification of SMEs by early warning model based on data mining'. A. World academy of science, engineering and technology, open science index 70," International Journal of Economics and Management Engineering, vol. 6, no. 10, pp. 2649-2660, 2012.

[32] P. G. George and V. R. Renjith, "Evolution of safety and security risk assessment methodologies towards the use of bayesian networks in process industries," Journal of Process Safety and Environmental Protection, vol. 149, pp. 758-775, 2021.

[33] A. Tantawy and S. Abdelwahedme)"[?--]>, "Model-based risk assessment for cyber physical systems security," Journal of Computer Security, vol. 96, Article ID 101864, 2020.

[34] X. Chen, Z. Lianhong, M. Li et al., "Review on the research status of power system risk identification under typhoon disaster," Journal of Procedia Computer Science, vol. 155, pp. 780-784, 2019. 
[35] C. Sun and Z. Bie, "Fuzzy copula model for wind speed correlation and its application in wind curtailment evaluation," Journal Renewable Energy, vol. 93, pp. 68-76, 2016.

[36] M. Aliabadi, E. Taheri, and K. Najafi, "Structural equation modeling of risk-taking behaviors based on personality dimensions and risk power," Journal of International Archives of Health Sciences, vol. 7, no. 3, pp. 119-125, 2020.

[37] E. Ciapessoni, D. Cirio, and A. Pitto, "A risk-based methodology and tool combining threat analysis and power system security assessment," Journal of Energies, vol. 11, no. 1, p. 83, 2017. 